\title{
ANÁLISE FLORÍSTICA E ESTRUTURAL DE UMA ÁREA DE CAATINGA PRESERVADA NO MUNICÍPIO DE MOSSORÓ/RN
}

\author{
Lívia laiane Barbosa Alves, Allyson Rocha Alves, \\ Francisco Rodolfo da Silva Barreto, Alan Cauê de Holanda \\ Universidade Federal Rural do Semi-árido - UFERSA \\ $<$ liviabarbosa17@yahoo.com.br>,<allyson@ufersa.edu.br> \\ <rodolfo_eng.florestal@hotmail.com>,<holandaac@yahoo.com.br> \\ DOI: $10.21439 /$ conexoes.v11i1.1066
}

\begin{abstract}
Resumo. Na região Nordeste do Brasil predomina o bioma Caatinga, marcado pelo clima semiárido e vegetação que apresenta diversas fitofisionomias, adaptadas a extremas condições de seca. O objetivo desta pesquisa foi a obtenção de informações sobre a cobertura vegetal de um remanescente de caatinga preservado por 30 anos após o corte no município de Mossoró-RN. O experimento foi desenvolvido em um fragmento florestal com 15,30 ha de área experimental, onde foram alocadas aleatoriamente seis parcelas de $20 \mathrm{~m}$ x $20 \mathrm{~m}\left(400 \mathrm{~m}^{2}\right)$, de acordo com critérios da Rede de Manejo Florestal da Caatinga, responsável pela instalação do experimento há 30 anos. Mensurou-se (circunferência e altura) e identificou-se com plaquetas todos os indivíduos com CAP (Circunferência à Altura do Peito) $\geq 6$ $\mathrm{cm}$. Os dados coletados em campo foram processados com auxílio do software Mata Nativa 3.0, em que foram analisados todos os parâmetros fitossociológicos: densidades, frequências, dominâncias e, índice de valor de importância, e a distribuição dos indivíduos pelas classes de diâmetro e altura. Também foi analisado o índice de diversidade de Shannon (H'). Foram amostrados um total de 1392 indivíduos de 10 famílias, 21 espécies e 16 gêneros. A espécie com maior número de representantes foi a Bauhinia cheilantha. As espécies com maior importância ecológica na área foram: Bauhinia cheilantha, Poincianella bracteosa e Mimosa ophthalmocentra. O índice de Shannon-Weaver encontrado para a área em estudo foi de 2,31 nats.ind ${ }^{-1}$. Concluiu-se que a área estudada após sofrer intervenção antrópica, regenerou-se naturalmente e se encontra atualmente em estágios de sucessão secundária, fato este observado através da presença de espécies pioneiras e secundárias.
\end{abstract}

Palavras-chaves: Diversidade, sucessão, distribuição diamétrica.

\begin{abstract}
In northeastern's Brazil dominates the Caatinga biome, marked by the semi-arid climate and vegetation that has several physiognomy, adapted to extreme drought conditions. The objective of this research was to obtain information on plant cover of a remnant of Caatinga preserved 30 years after cutting in the city of Mossoró-RN. The experiment was conducted in a forest fragment with 15.30 ha experimental area, where they were randomly leased six plots of $20 \mathrm{mx} 20 \mathrm{~m}\left(400 \mathrm{~m}^{2}\right)$, according to criteria of the Rede de Manejo Florestal da Caatinga, responsible for the experiment 30 years ago. We measured up (circumference and height) and identified with platelet all individuals with $\mathrm{CBH}$ (circumference at breast height) $\geq 6 \mathrm{~cm}$. The data collected in the field were processed with the help of the software Mata Nativa 3.0, which examined all phytosociology: densities, frequencies, dominances, and the distribution of individuals by diameter and height classes. Also analyzed importance value index Shannon diversity index ( $\mathrm{H}^{\prime}$ ') We sampled a total of 1392 individuals of 10 families, 21 species, and 16 genera. The specie with the highest number of representatives was the Bauhinia cheilantha. The species with higher ecological importance in the area were: Bauhinia cheilantha, Poincianella bracteosa and Mimosa ophthalmocentra. The Shannon-Weaver index found for the study area was 2.31 nats.ind $^{-1}$. It was concluded that the studied area after suffering human intervention regenerated naturally and is in stages of secondary succession, a fact observed by the presence of pioneer and secondary species.
\end{abstract}

Keywords: Diversity, succession, diameter distribution. 


\section{INTRODUÇÃO}

A Caatinga é o principal bioma da região Nordeste do Brasil, ocupando uma área de $844.453 \mathrm{~km}^{2}$, o equivalente a 11\% do território nacional (MMA, 2014). Apesar de estar localizado em uma região de clima semiárido, o bioma apresenta grande variedade paisagística, elevada riqueza biológica e várias espécies endêmicas. A vegetação é constituída, especialmente, de espécies lenhosas e herbáceas, de pequeno porte, geralmente dotadas de espinhos, sendo, comumente, caducifólias, ou seja, perdem suas folhas no início da estação seca, além de cactáceas e bromeliáceas (DRUMOND et al. 2000). O clima semiárido apresenta condições preponderantes na formação do bioma, individualizando as características preservativas das espécies vegetais (SOUZA; MEDEIROS 2013). A Caatinga possui um imenso potencial para a conservação de serviços ambientais e uso sustentável, que se bem explorado poderá ser decisivo para o desenvolvimento econômico do país (MMA 2014). Porém, a Caatinga tem sofrido expressivo processo de degradação, provocado geralmente pelo desmatamento, devido à ocupação de áreas com atividades agrícolas e de pecuária e utilização imprópria dos recursos naturais (DRUMOND et al., 2000). Dentre as causas desse processo podemos citar a retirada de vegetação para fins agrícolas, de pastoreio e exploração de lenha.

Uma boa gestão dos recursos naturais é fundamental para garantir a capacidade de reprodução das espécies e consequentemente sua conservação ao longo do tempo. As unidades de conservação têm sido grandes aliadas nessa gestão. Paralelo a isso, o manejo florestal vem tomando espaço como uma forma de administração dos bens e serviços florestais associados ao desenvolvimento econômico. No Rio Grande do Norte a utilização das florestas tem diversos objetivos e delas pode-se obter uma ampla variedade de produtos e benefícios (MOREIRA et al. 2007).

É necessário conhecer os diferentes ecossistemas florestais, suas limitações, sua capacidade de recuperação, e principalmente sua composição faunística e florística, para que assim as florestas sejam manejadas de forma correta. Em termos de Caatinga, ainda se tem poucos estudos relacionados ao bioma na área de fitossociologia e florística.

O número de espécies vegetais encontrado no bioma Caatinga ainda não é registrado com precisão, porém, sabe-se que esse valor tende a aumentar à medida que são descobertas novas espécies. Dentre as mais conhecidas, pode-se citar: a catingueira (Poincianella bracteosa), jurema branca (Piptadenia stipulaceae), jurema preta (Mimosa tenuiflora), jurema de imbira (Mimosa ophthalmocentra), aroeira (Myracroduon urundeuva), marmeleiro (Croton blanchetianus), mororó (Bauhinia cheilantha), sabiá (Mimosa caesalpinifolia), facheiro (Pilosocereus pachycladus), além das diversas espécies herbáceas. Entre os principais produtos fornecidos pelas espécies da Caatinga estão: a lenha, o carvão vegetal, madeiras para construção civil e serrarias, produtos medicinais, forragem animal, além de abrigo para a fauna silvestre e um alto potencial apícola.

A fitossociologia traz, em dados numéricos, informações sobre a estrutura e comportamento de uma população vegetal, em termos quantitativos e qualitativos. A análise da estrutura de uma floresta é feita com base nas dimensões das plantas e suas distribuições (MOREIRA, 2014). Dessa forma, os estudos florísticos e fitossociológicos são fundamentais para o conhecimento de ecossistemas florestais, visando um manejo adequado ou para fins de conservação ecológica.

Segundo Martins (1989) e Pereira(2000) (apud Moreira et al. (2007) é através da aplicação de um método fitossociológico que pode-se avaliar momentaneamente a estrutura da vegetação, através da frequência, densidade e dominância das espécies ocorrentes em uma determinada comunidade.

A realização do manejo florestal racional é fundamental para a exploração de forma sustentável dos recursos naturais. Vários estudos já mostraram que as florestas manejadas corretamente podem proporcionar maiores benefícios econômicos, sociais e ecológicos. Sendo assim, é essencial o estudo da vegetação, bem como suas potencialidades e restrições. Portanto, o objetivo dessa pesquisa foi a obtenção de informações sobre um remanescente de vegetação de Caatinga preservado 30 anos após o corte, no município de MossoróRN.

\section{MATERIAIS E MÉTODOS}

O presente estudo foi desenvolvido na Fazenda Belo Horizonte, propriedade pertencente ao grupo empresarial Itapetinga Agro Industrial, localizada no município de Mossoró, no estado do Rio Grande do Norte (Figura 11. O município de Mossoró situa-se na mesorregião Oeste Potiguar e na microrregião de Mossoró, apresentando uma área total de $2.110,207 \mathrm{~km}^{2}$, é composto por pouco mais de 280 mil habitantes; está localizado à margem de um rio perene, o rio Apodi-Mossoró, segundo maior rio potiguar, com cerca de $210 \mathrm{~km}$ de extensão, cortando vários municípios do estado.

Geologicamente o município de Mossoró encontrase inserido na Província Borborema, sendo constituído pelos sedimentos da Formação Jandaíra, do Grupo Barreiras, depósitos Colúvios-eluviais, Flúvio-lagunares e 


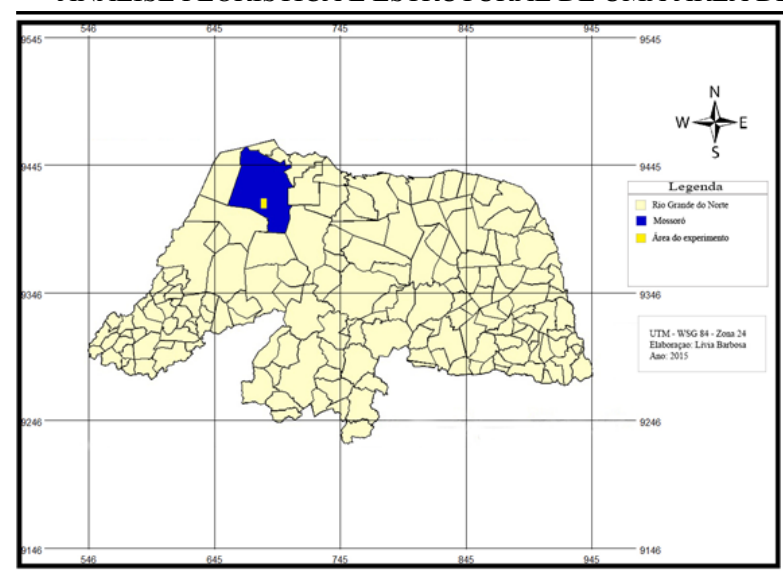

Figura 1: Mapa de localização da área do experimento em relação ao município de Mossoró e o estado do Rio Grande do Norte.

depósitos Aluvionares (CRPM, 2005).

O relevo da área estudada é considerado plano, o solo apresenta predominância de cambissolo eutrófico com alta fertilidade e latossolo vermelho amarelo eutrófico de fertilidade média a alta (IDEMA, 2008). Os cambissolos compreendem solos pouco desenvolvidos constituídos de horizonte B incipiente. Rochas e sedimentos diversificados constituem seu material de origem. Possui grande heterogeneidade de atributos morfológicos, físicos, químicos e mineralógicos. Devido à diversidade do material de origem, das formas de relevo e das condições climáticas, as características destes solos variam muito de um local para outro (EMBRAPA. 2006). Os Latossolos são constituídos de material mineral com horizonte B latossólico que apresentam avançado estado de intemperização, Apresenta características morfológicas, físicas, químicas e mineralógicas uniformes no perfil. Exibe cores vermelhas, vermelhoamarelas, amarelas, acinzentadas ou brunadas. Ocorre comumente em relevo suave, de ondulado a plano, acidentado, inclusive em relevo montanhoso. São originados a partir das mais diversas espécies de rochas e sedimentos, sob condições de clima e tipos de vegetação os mais diversos (EMBRAPA, 2006).

O clima de Mossoró é classificado como Tipo BSwh', segundo Köppen, clima muito seco, sendo a maior incidência de chuvas no verão, atrasando para o outono (ALVARES et al. 2014). Geralmente apresenta um volume de precipitação média anual na faixa de 800 $\mathrm{mm}$ (podendo variar para mais ou menos), a amplitude térmica é mais ou menos de $2^{\circ} \mathrm{C}$, com temperatura média anual de $27,4{ }^{\circ} \mathrm{C}$ e umidade relativa do ar média anual de $70 \%$, segundo dados do Instituto Nacional de Meteorologia (INMET, 2014). A vegetação do local em estudo é do tipo Caatinga hiperxerófila, vegetação de caráter mais seco, com abundância de cactáceas e plantas de porte mais baixo e espalhado (IDEMA, 2008).

Foi realizado inventário florestal numa área experimental de 15,30 ha (Figura 2) de Caatinga preservada por 30 anos após a realização do corte raso e corte seletivo, onde foram alocadas aleatoriamente seis parcelas de $20 \mathrm{~m}$ x $20 \mathrm{~m}\left(400 \mathrm{~m}^{2}\right)$ totalizando uma área de 2400 $m^{2}$. Foram escolhidas seis parcelas segundo RMFC (2005), visto que o experimento inicial, há 30 anos, foi implantado pela mesma. Os indivíduos mensurados foram marcados com plaquetas de alumínio numeradas em todas as unidades amostrais. Foram amostrados todos os indivíduos que apresentaram CAP (Circunferência à Altura do Peito) $\geq 6 \mathrm{~cm}$, e mensuradas suas respectivas alturas totais, seguindo as instruções da RMFC. Para medição da circunferência $(\mathrm{cm})$ foi utilizado uma fita métrica e para estimativa da altura (m) uma régua graduada. Os dados coletados em campo foram processados no software Mata Nativa 3.0, onde foram analisados os seguintes parâmetros fitossociológicos: densidades, frequências, dominâncias e índice de valor de importância e também o índice de diversidade de Shannon-Weaner (H').

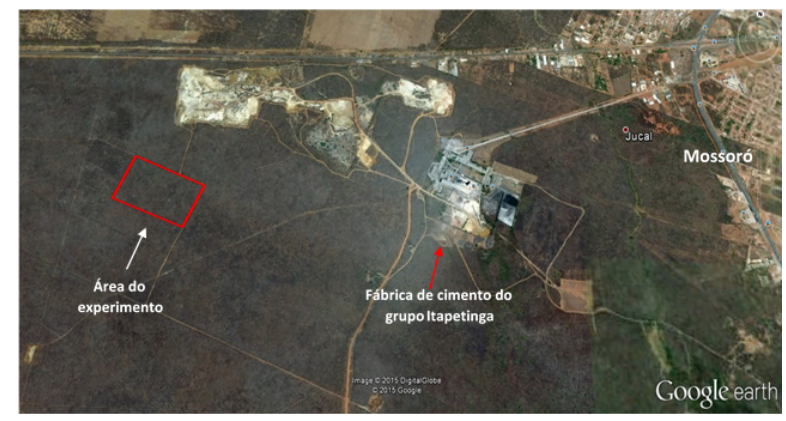

Figura 2: Localização da área do experimento em relação ao município de Mossoró/RN

Fonte: Google Earth, 2015

\section{RESULTADOS E DISCUSSÃO}

Um total de 1392 indivíduos foi mensurado, pertencentes a 10 famílias, 16 gêneros e 21 espécies, sendo $M i$ mosa ophthalmocentra e Croton sonderianus as únicas espécies comuns às seis parcelas. Holanda et al. (2015) amostrou em um remanescente de Caatinga preservado há 50 anos 1155 indivíduos pertencentes a oito famílias e doze espécies. A quantidade de espécies encontradas pode ser considerada satisfatória, visto que para alguns estudos em áreas de Caatinga o número de espécies está entre 5 e 70 (ALVES et al., 2013, SILVA 
et al. ; ALCORADO-FILHO; SAMPAIO; RODAL 2003; MOREIRA et al., 2007). A listagem das espécies encontradas, bem como as respectivas famílias às quais pertencem, encontra-se na Tabela 1 . É importante destacar que o número de espécies registradas em uma área irá depender de diversos fatores como, topografia, geologia, pedologia, temperaturas, pluviometria e a própria interferência antrópica.

A família que apresentou maior número de representantes foi a Fabaceae/Caesapinioideae com um total de 488 indivíduos e a espécie com maior número de representantes foi a Bauhinia cheilantha, com 255 indivíduos, seguido da Poincianella bracteosa com 233 e a Croton sonderianus com 200 indivíduos. A maior densidade encontrada foi a da espécie Bauhinia cheilantha, com 1062,5 ind.ha ${ }^{-1}$.

A espécie de maior importância ecológica para a área, Bauhinia cheilantha, vulgarmente conhecida como mororó ou pata-de-vaca, é uma planta arbustivoarbórea que apresenta ocorrência em todo o Nordeste do Brasil segundo dados do CNIP (2015). Entre suas utilidades apresenta alto potencial medicinal nas suas folhas e casca do tronco, é utilizada para alimentação animal, além de ser bastante utilizada para a construção de cercas vivas, recuperação de áreas degradadas em sua primeira fase, e a madeira pode ser usada como lenha, estaca e para a produção de carvão.

A comunidade apresentou fitofisionomia fechada em algumas áreas e mais aberta em outras. Foi observada uma densidade total de 5800 ind.ha $^{-1}$ valor mais representativo que 3250 ind.ha $^{-1}$ encontrado por Amorim, Sampaio e Araújo (2005), em um estudo realizado na Estação Ecológica do Seridó, município de Serra Negra do Norte-RN. Alves et al. (2013) registraram em uma área de Caatinga no Piauí densidade de 1600 ind.ha $^{-1}$, também inferior ao número encontrado no presente estudo. A área basal total estimada no software Mata Nativa 3.0 foi de $12,85 \mathrm{~m}^{2}$.ha ${ }^{-1}$, inferior ao encontrado por Alves et al. (2013) e Silva et al. (), de $17,07 \mathrm{~m}^{2} \cdot \mathrm{ha}^{-1}$ e $14,06 \mathrm{~m}^{2} \cdot \mathrm{ha}^{-1}$, respectivamente. Isso significa que a área estudada apresentou um número maior de indivíduos em comparação com as outras áreas, porém, com menor volume madeireiro. Fato que pode ser explicado devido as condições de sítio diferentes para cada local. $\mathrm{O}$ volume total por hectares encontrado foi de $85,95 \mathrm{~m}^{3} \cdot \mathrm{ha}^{-1}$. Na Tabela 2 podem ser observados todos os parâmetros fitossociológicos encontrados na área estudada.

O valor de impotância (VI) é um estimador da importância ecológica de um táxon dentro de uma comunidade florestal. É calculado pela soma da densidade relativa (DR), da dominância relativa (DoR) e da frequên- cia relativa (FR) de determinada espécie. Portanto, este índice apresenta uma melhor definição para a importância ecológica da espécie, observando a sua distribuição não apenas do ponto de vista horizontal ou vertical, mas, pelo somatório das suas análises. Na Figurd3 é possível observar as dez espécies com maior VI, que juntas representam $80,84 \%$ do VI total. Sabino, Cunha e Santana (2016) verificaram um total de 92,47\% para as 10 espécies com maior VI. As quatro espécies com maior VI na área em estudo (Bauhinia cheilantha, Poincianella bracteosa, Mimosa ophthalmocentra e Croton blanchetianus) são as de maior importância ecológica local por se apresentarem em maior número, devido a capacidade de adaptação a condições de seca e baixa exigência em solos férteis que estas espécies possuem, e ao se estabelecerem naquela área contribuem para a melhoria do solo, facilitando a chegada de outras espécies naquele ambiente. Ou seja, estas espécies foram as que apresentaram maior importância ecológica, contribuindo de forma mais significativa para o equilíbrio ambiental da área estudada.

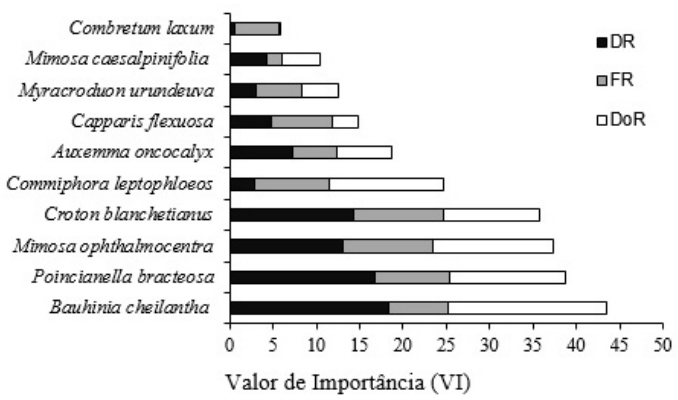

Figura 3: Dez espécies amostradas na Fazenda Belo Horizonte com maior valor de importância, representados pela soma da Densidade Relativa (DR), Frequência Relativa (FR) e Dominância Relativa (DoR).

A análise da distribuição diamétrica mostrou que as espécies amostradas seguiram a tendência de distribuição do J-Invertido (Figura 4), ou seja, apresentam um número maior de indivíduos nas menores classes de diâmetro. Segundo Moreira (2014) esta é uma característica de florestas inequiâneas e pode ser uma estratégia de se restabelecer após intervenções antrópicas e longos períodos de seca. Portanto, o ambiente estudado apresenta elevado número de indivíduos regenerantes, devido aos menores números de diâmetros encontrados. Caso venha a ocorrer alguma perturbação na vegetação e os indivíduos com idade mais avançada, que ocorrem em menor quantidade possam vir a morrer, os demais indivíduos jovens, junto com os regene- 
Tabela 1: Relação florística das espécies da Fazenda Belo Horizonte, no município de Mossoró-RN

\begin{tabular}{l|l|l}
\hline Família & Espécie & Nome Comum \\
\hline Anacardiaceae & Myracroduon urundeuva Allemao & Aroeira \\
Bignoniaceae & Tabebuia impetiginosa (Mart. Ex DC.) Standl. & Ipê roxo \\
Boraginaceae & Auxemma oncocalyx (Allemao) Taub. & Pau branco \\
Boraginaceae & Cordia leucocephala (Jacq.) Humb., Bompl. \& Kunth. & Maria preta \\
Burseraceae & Commiphora leptophloeos (Mart.) J.B.Gillett & Imburana \\
Capparaceae & Capparis flexuosa L. & Feijão bravo \\
Combretaceae & Combretum leprosum Mart. & Mofumbo \\
Combretaceae & Combretum laxum Jacq. & Cipó bugi \\
Euphorbiaceae & Croton sonderianus Muell.Arg. & Marmeleiro preto \\
Euphorbiaceae & Manihot glaziovi Mull.Arg. & Maniçoba \\
Euphorbiaceae & Jatropha mollissima (Pohl) Baill. & Pinhão bravo \\
Euphorbiaceae & Jatropha curcas L. & Pinhão manso \\
Fabaceae/Caesapinioideae & Poincianella bracteosa (Tul.) L.P. Queiroz & Catingueira \\
Fabaceae/Caesapinioideae & Bauhinia cheilantha (Bong.) Steud. & Mororó \\
Fabaceae/Mimosoideae & Piptadenia stipulaceae (Benth.) Ducke & Jurema branca \\
Fabaceae/Mimosoideae & Mimosa ophthalmocentra Mart. & Jurema de imbira \\
Fabaceae/Mimosoideae & Mimosa tenuiflora Poir. & Jurema preta \\
Fabaceae/ Mimosoideae & Mimosa caesalpinifolia Benth. & Sabiá \\
Nyctaginaceae & Pisonia tomentosa Casar. & João mole \\
Rhamnaceae & Ziziphus joazeiro Mart. & Juazeiro \\
\hline
\end{tabular}

Tabela 2: Parâmetros fitossociológicos das espécies amostradas na Fazenda Belo Horizonte, no município de Mossoró-RN (DA - Densidade Absoluta, DR(\%) - Densidade Relativa, FA(\%) - Frequência Absoluta, FR(\%) - Frequência Relativa, DoA - Dominância Absoluta, DoR(\%) - Dominância Relativa e VI(\%) - Valor de Importância)

\begin{tabular}{l|cccccccc}
\hline Nome Científico & N & DA & DR & FA & FR & DoA & DoR & VI \\
Bauhinia cheilantha & 255 & 1062,50 & 18,32 & 66,67 & 6,90 & 2,33 & 18,18 & 14,47 \\
Poincianella bracteosa & 233 & 970,83 & 16,74 & 83,33 & 8,62 & 1,72 & 13,44 & 12,93 \\
Mimosa ophthalmocentra & 183 & 762,50 & 13,15 & 100,00 & 10,34 & 1,79 & 13,93 & 12,47 \\
Croton sonderianus & 200 & 833,33 & 14,37 & 100,00 & 10,34 & 1,42 & 11,07 & 11,93 \\
Indeterminadas & 142 & 591,66 & 10,20 & 100,00 & 10,34 & 1,09 & 8,47 & 9,67 \\
Commiphora leptophloeos & 41 & 170,83 & 2,95 & 83,33 & 8,62 & 1,69 & 13,15 & 8,24 \\
Auxemma oncocalyx & 101 & 420,83 & 7,26 & 50,00 & 5,17 & 0,80 & 6,24 & 6,22 \\
Capparis flexuosa & 68 & 283,33 & 4,89 & 66,67 & 6,90 & 0,39 & 3,11 & 4,96 \\
Myracroduon urundeuva & 43 & 179,16 & 3,09 & 50,00 & 5,17 & 0,56 & 4,37 & 4,21 \\
Mimosa caesalpinifolia & 59 & 245,83 & 4,24 & 16,67 & 1,72 & 0,56 & 4,39 & 3,45 \\
Combretum laxum & 8 & 33,33 & 0,57 & 50,00 & 5,17 & 0,01 & 0,13 & 1,96 \\
Pisonia tomentosa & 29 & 120,83 & 2,08 & 16,67 & 1,72 & 0,23 & 1,78 & 1,86 \\
Mimosa tenuiflora & 4 & 16,66 & 0,29 & 33,33 & 3,45 & 0,11 & 0,86 & 1,53 \\
Piptadenia stipulaceae & 3 & 12,50 & 0,22 & 33,33 & 3,45 & 0,03 & 0,23 & 1,30 \\
Combretum leprosum & 7 & 29,16 & 0,50 & 16,67 & 1,72 & 0,02 & 0,14 & 0,79 \\
Ziziphus joazeiro & 5 & 20,83 & 0,36 & 16,67 & 1,72 & 0,01 & 0,12 & 0,73 \\
Tabebuia impetignosa & 4 & 16,66 & 0,29 & 16,67 & 1,72 & 0,02 & 0,18 & 0,73 \\
Manihot glaziovi & 2 & 8,33 & 0,14 & 16,67 & 1,72 & 0,07 & 0,05 & 0,64 \\
Jatropha mollissima & 2 & 8,33 & 0,14 & 16,67 & 1,72 & 0,05 & 0,04 & 0,64 \\
Cordia leucocephala & 2 & 8,33 & 0,14 & 16,67 & 1,72 & 0,04 & 0,03 & 0,63 \\
Jatropha curcas & 1 & 4,16 & 0,07 & 16,67 & 1,72 & 0,07 & 0,06 & 0,62 \\
\hline Total & 1392 & 5800,00 & 100,00 & 966,67 & 100,00 & 12,84 & 100,00 & 100,00 \\
\hline
\end{tabular}


rantes, de maneira rápida irão repovoar a área afetada (PEREIRA-JUNIOR; ANDRADE; ARAúJO, 2012). A maior frequência de indivíduos nas classes menores significa que esta vegetação ainda não está em seu estágio de sucessão mais avançado, e ainda se encontra em processo de regeneração após sofrer interferência antrópica.

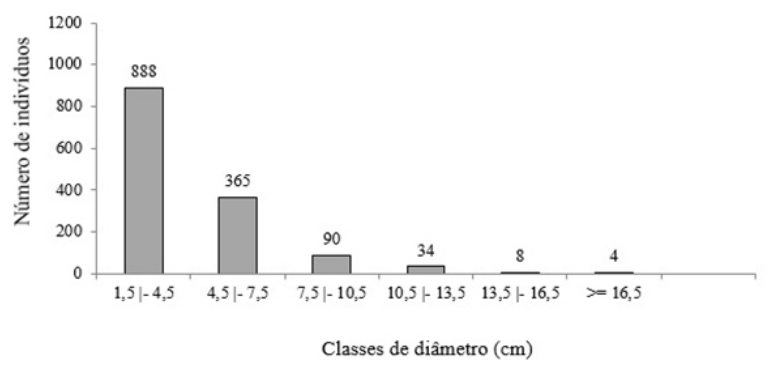

Figura 4: Distribuição diamétricas dos indivíduos amostrados na Fazenda Belo Horizonte, no município de Mossoró-RN.

Com relação à altura, os indivíduos mensurados foram separados em três classes diferentes, onde a maior parte dos indivíduos (976) amostrados apresentaram alturas entre 4,50 m e 7,50 m (Figura 5). A maior altura registrada foi de um indivíduo de mororó (Bauhinia cheilantha) com 13,5 m. Amorim, Sampaio e Araújo (2005) encontrou apenas duas plantas com altura maior que $8 \mathrm{~m}$, em estudo realizado no Seridó do Rio Grande do Norte. A altura média para a área do experimento foi de aproximadamente $5,3 \mathrm{~m}$, valor menor que o encontrado por Silva et al. () que observou uma altura média de 7,14 m em uma área de Caatinga arbórea no estado do Piauí. Porém, o valor para a área em estudo foi maior que o encontrado por Rodal, Costa e Lins (2008) que verificou uma altura média de 2,37 m para uma área de Caatinga no sertão de Pernambuco. Portanto, baseado nas alturas dos indivíduos encontrados na área estudada, pode-se caracterizar a vegetação área como arbustivo-arbórea, e que a mesma se encontra em estágio de sucessão secundário, visto que a maioria das espécies identificadas são pertences aos grupos das pioneiras, secundárias iniciais e tardias.

A diversidade está relacionada com a variabilidade de espécies encontradas em uma determinada população, habitat ou região. O índice de diversidade de Shannon-Weaver (H') é um dos índices usados para avaliar a diversidade em dados categóricos, levando em consideração o número de espécies e o número total de indivíduos. Quanto maior esse índice, maior será a diversidade da área. O índice de Shannon-Weaver encontrado para a área em estudo foi de 2,31 nats.ind ${ }^{-1}$, valor superior a 2,13 nats.ind ${ }^{-1}$ encontrado por Moreira

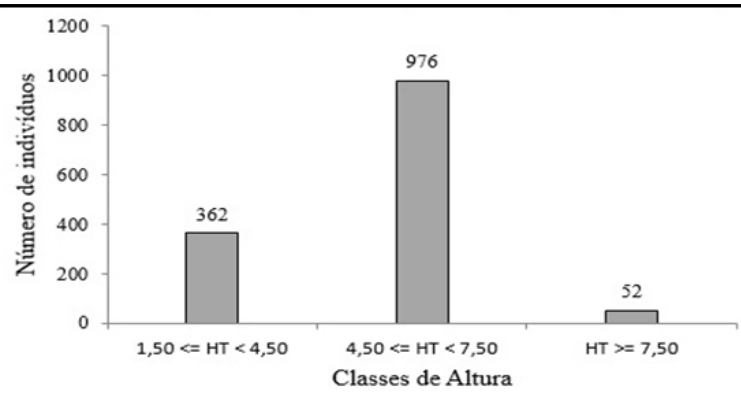

Figura 5: Distribuição do número de indivíduos por classe de altura na Fazenda Belo Horizonte, no município de Mossoró-RN.

(2014) em uma área de Caatinga no interior da Paraíba, 2,29 nats.ind-1 encontrado por Pereira-Junior, Andrade e Araújo (2012), no município de Monteiro/Paraíba e 1,33 nats.ind ${ }^{-1}$ registrado por Dantas et al. (2010). O valor encontrado pode ser considerado baixo quando comparado com outras formações florestais tais como Floresta Ombrófila e Floresta Estacional, porém, para áreas de Caatinga é um valor satisfatório visto que a maioria dos valores encontrados para essas áreas estão entre 1,91 a 3,09 (ALCORADO-FILHO; SAMPAIO; RODAL, 2003; ARAÚJO; SAMPAIO; RODAL, 1995. FERRAZ et al., 1998, LYRA, 1982, RODAL; SAMPAIO; FIGUEIREDO, 1992; RODAL et al., 1998).

\section{CONCLUSÕES}

A análise da vegetação da área estudada permitiu verificar que as famílias com maior número de representantes foram: Fabaceae/Caesapinoideae, Fabaceae/Mimosoideae e Euphorbiaceae, que juntas representam 64,8\% dos indivíduos amostrados.

As espécies com maior importância ecológica na área foram Bauhinia cheilantha, Poincianella bracteosa e Mimosa ophthalmocentra, o que representa a dominância das mesmas na comunidade, pelo fato de se desenvolverem em condições ambientais extremas, e indicar que a vegetação encontra-se em estágio de sucessão secundária, devido à presença desses indivíduos e de outros também encontrados nesse estudo.

Também se verificou a presença de muitas espécies pioneiras, o que indica um alto número de espécies regenerantes, devido a interferência antrópica que a área sofreu. E que após 30 anos da exploração, a área estudada se encontra em estágio de sucessão secundário e apresenta uma diversidade considerada satisfatória para áreas de Caatinga arbustivo-arbórea na região. 
ANÁLISE FLORÍSTICA E ESTRUTURAL DE UMA ÁREA DE CAATINGA PRESERVADA NO MUNICÍPIO DE MOSSORÓ/RN

\section{REFERÊNCIAS}

ALCORADO-FILHO, F. G.; SAMPAIO, E. V. S. B.; RODAL, M. J. N. Florística e fitossociologia de um remanescente de vegetação caducifólia espinhosa arbórea em Caruaru, Pernambuco. Acta Botânica Brasílica, v. 17, n. 2, p. 287-303, 2003.

ALVARES, C. A.; STAPE, J. L.; SENTELHAS, P. C.; GONCALVES, J. L. M.; SPAROVEK, G. Koppen's climate classification map for Brazil. Meteorologische Zeitschrift, v. 22, n. 6, p. 711-728, 2014.

ALVES, A. R.; RIBEIRO, I. B.; SOUSA, J. R. L.; BARROS, S. S.; SOUSA, P. R. Análise da estrutura vegetacional em uma área de Caatinga no município de Bom Jesus, Piauí. Revista Caatinga, v. 26, n. 4, p. 99-106, 2013.

AMORIM, I. L. d.; SAMPAIO, E. V. S. B.; ARAúJO, E. d. L. Flora e estrutura da vegetação arbustivo arbórea de uma área de caatinga do Seridó, RN, Brasil. Acta Botânica Brasilica, v. 19, n. 3, p. 615-623, 2005.

ARAÚJO, E. L.; SAMPAIO, E. V. S. B.; RODAL, M. J. N. Composição florística e fitossociológica de três áreas de caatinga de Pernambuco. Revista Brasileira de Biologia, v. 55, n. 4, p. 615-623, 1995.

CNIP. Banco de dados de plantas do Nordeste: Bauhinia cheilantha. Cetro Nordestino de Informações sobre Plantas, 2015. Disponível em: $<$ http://www.cnip.org.br/bdpn/ficha.php?cookieBD= cnip7\&taxon=1278> Acesso em: ago. 2015.

CRPM. Projeto cadastro de fontes de abastecimento por água subterrânea Rio Grande do Norte: Diagnóstico do Município de Mossoró. : Serviço Geológico do Brasil, 2005.

DANTAS, J. G.; HOLANDA, A. C.; SOUTO, L. S.; JAPIASSU, A.; HOLANDA, E. M. Estrutura do componente arbustivo/arbóreo de uma área de Caatinga situada no município de Pombal-PB. Revista Verde de Agroecologia e Desenvolvimento Sustentável., v. 3, n. 11, p. 134-142, 2010.

DRUMOND, M. A.; KIILL, L. H. P.; LIMA, P. C. F.; OLIVEIRA, M. C.; OLIVEIRA, V. R.; ALBUQUERQUE, S.; NASCIMENTO, C.

E. S.; CAVALCANTE, J. Estratégias para o uso sustentável da biodiversidade da caatinga. In: EMBRAPA/CPATSA, U. e. C. I. d. B. (Ed.). Seminário para avaliação e identificação de ações prioritárias para a conservação, utilização sustentável e repartição de beneficios da biodiversidade do bioma Caatinga. Petrolina: , 2000.
EMBRAPA. Sistema brasileiro de classificação de solos. 2. ed. Rio de Janeiro, 2006.

FERRAZ, E. M. N.; RODAL, M. J. N.; SAMPAIO, E. V. S. B.; PEREIRA, R. C. A. Composição florística em trechos de vegetação de caatinga e brejo de altitude na região do Vale do Pajeú, Pernambuco. Revista Brasileira de Botânica, v. 21, n. 1, p. 7-15, 1998.

HOLANDA, A. C.; LIMA, F. T. D.; SILVA, B. M.; DOURADO, R. G.; ALVES, A. R. Estrutura da vegetação em remanescentes de Caatinga com diferentes históricos de perturbação em Cajazeirinhas (PB). Revista Caatinga, v. 28, n. 4, p. 142-150, 2015.

IDEMA. Perfil do seu Município. 2008. Instituto de Desenvolvimento Sustentável e Meio Ambiente - IDEMA. Disponível em: <http://www.idema.rn.gov.br> Acesso em: out. 2014.

INMET. Estações Automáticas - Mossoró.

2014. Instituto Nacional de Meteorologia - INMET.

Disponível em: <http://www.inmet.gov.br/portal/index. php?r=home/page\&page=rede_estacoes_auto_graf $>>$ Acesso em: jul. 2014.

LYRA, A. L. R. T. A condição de brejo: efeito do relevo na vegetação de duas áreas do Município do Brejo de Madre de Deus, PE. Dissertação (Mestrado) - Universidade Federal Rural de Pernambuco, Recife, 1982.

MARTINS, F. R. Fitossociologia de Florestas no Brasil: um histórico bibliográfico. Pesquisas - Série Botânica, n. 40, p. 103-164, 1989.

MMA. Biomas and Caatinga. 2014. Ministério do Meio Ambiente (MMA). Disponível em: <http://www.mma.gov.br/biomas/caatinga $>$ Acesso em: out. 2014

MOREIRA, A. R. P.; MARACAJA, P. B.; GUERRA, A. M. N. M.; FILHO, F. A. S.; PEREIRA, T. F. C. Composição florística e análise fitosociológica arbustivo-arbóreo no município de caraúbas-RN. Revista Verde de Agroecologia e Desenvolvimento Sustentável, v. 2, n. 1, p. 113-126, 2007.

MOREIRA, F. Florística, fitossociologia e corte seletivo pelo método BDq em uma área de Caatinga, no município de São José de Espinharias - PB. Dissertação (Mestrado) - Ciências Florestais.CSTR/UFCG, Patos $-\mathrm{PB}, 2014$

PEREIRA, I. M. Levantamento Florístico do Estrato Arbustivo-Arbóreo e Análise da Estrutura 
Fitossociológica de Ecossistema de Caatinga sob Diferentes Niveis de Antropismo. Dissertação (Mestrado) - UFPB, 2000.

PEREIRA-JUNIOR, L. R.; ANDRADE, A. P. d.; ARAúJO, K. D. Composição florística e fitossociológica de um frragmento de caatinga em monteiro, PB. Revista Holos, v. 6, n. 3, p. 15-22, 2012.

RMFC. Protocolo de medições de parcelas permanentes. Recife: Rede de Manejo Florestal da Caatinga. Comitê Técnico Científico. Associação Plantas do Nordeste, 2005. Disponível em: $<$ http://www.mma.gov.br/biomas/caatinga $>$. Acesso em: out. 2014.

RODAL, M. J. N.; ANDRADE, K. V. d. A.; SALES, M. F.; GOMES, A. P. S. Fitossociologia do componente lenhoso de um refúgio vegetacional no município de Buíque, pe. Revista Brasileira de Biologia, v. 58, n. 3, p. 517-526, 1998.

RODAL, M. J. N.; COSTA, K. C. C.; LINS, A. C. B. Estrutura da Vegetação Caducifólia Espinhosa (Caatinga) de uma área do sertão central de Pernambuco. Revista Hoehnea, v. 35, n. 2, p. 209-217, 2008.

RODAL, M. J. N.; SAMPAIO, E. V. S.; FIGUEIREDO, M. A. Manual sobre métodos de estudo florístico e fitossociológico: ecossistema caatinga. Sociedade Botânica do Brasil, 1992.

SABINO, F.; CUNHA, M. C. L.; SANTANA, G. M. Estrutura da Vegetação em Dois Fragmentos de Caatinga Antropizada na Paraíba. Revista Floresta e Ambiente, , v. 23, n. 4, 2016.

SILVA, L. S.; ALVES, A. R.; HOLANDA, A. C.; NUNES, A. K. A.; MACEDO, W. S.; MARTINS, A. R. Estrutura e sucessão ecológica de um remanescente de mata ciliar na bacia do Rio Gurguéia - PI, journal = Revista Nativa, year $=2013$, volume $=3$, number $=3$, pages $=156-164$,

SOUZA, G. F.; MEDEIROS, J. F. Fitossociologia e florística em áreas de Caatinga na Microbacia Hidrográfica do Riacho Cajazeiras-RN. Revista GeoTemas, v. 3, n. 1, p. 161-176, 2013. 